\title{
La biblioteca invisible del IV Duque de Uceda (1649-1718)
}

\author{
Margarita MARTÍN VELASCO \\ (Centro Universitario Villanueva -Biblioteca-, adscrito a la Universidad \\ Complutense de Madrid)
}

\section{Resumen}

El bibliotecario del IV Duque de Uceda en Sicilia elaboró en 1692 un cuidadoso inventario acompañando la solicitud del traslado de los libros de Palermo a Madrid que ha sido objeto de numerosos estudios. Aquellos libros siguieron una particular fortuna que los llevó a la actual Biblioteca Nacional de España, con su peculiar encuadernación en pergamino verde. El cotejo del inventario de Uceda con el actual catálogo de la Biblioteca Nacional nos brindó la sorpresa de la presencia de numerosos libros con esta encuadernación que no fueron "declarados" al Santo Oficio y cuya pista hemos seguido en la presente investigación. Libros de astrología, de quiromancia, etc, algunos presentes en el índice, nos han permitido ampliar el conocimiento sobre la personalidad de su dueño y de su época, y hacer una clasificación de dichas obras para completar los estudios ya existentes.

Palabras clave: IV Duque de Uceda; Bibliotecas antiguas; Censura de libros.

\section{The invisible library of IV Duke of Uceda}

$$
\text { (1649-1718) }
$$

Abstract

The librarian of the IV Duke of Uceda in Sicily drafted in 1692 a careful inventory of the Duke's library to accompany a transfer request from Palermo to Madrid. These books, characterized by a distinctive green vellum binding, 
ended up in the National Library of Spain. A comparison of Uceda's inventory with the current catalog of the National Library produced the surprising result of the presence of many books with this bound that had not been "declared" the Holy Office. In this research we have followed the trail of these books on subjects such as Astrology, Quiromancy, etc. This investigation has enabled us to know more about the owner's personality and his age, and to classify them better.

Keywords: IV Duke of Uceda; Old libraries; Censorship of books.

\section{Introducción: un catálogo de 1692}

El inicio del presente trabajo está relacionado con el hallazgo de una documentación de carácter inquisitorial que Elisa Ruiz descubrió en el Archivo de la Nobleza, sección del Archivo Histórico Nacional, institución que conserva el fondo de los Duques de Uceda. En dicho fondo apareció un expediente que incluye la autorización del traslado de la colección de libros del IV Duque ${ }^{1}$ desde Palermo a Madrid, con motivo del cese en su cargo como virrey de Sicilia, con la condición de efectuar una inspección de censura de los libros registrados en una lista. La solicitud de autorización iba acompañada de un espléndido catálogo de la librería elaborado por el bibliotecario de Uceda.

El estudio de este catálogo fue el objeto de mi tesis doctoral, y, posteriormente fue publicado por la BNE, ya que aquellos libros permanecen allí desde la creación de la Real Biblioteca Pública por una circunstancia sobradamente conocida. ${ }^{2}$

Durante esta primera investigación tuve la fortuna de conseguir ${ }^{3}$ un listado de las signaturas de los libros que presentaban la encuadernación típica con que el Duque uniformó su colección. Mi sorpresa fue que muchos de aquellos libros no aparecían en el catálogo de 1692. Se abría una puerta para mí hacia una nueva búsqueda con la pregunta: ¿Por qué no incluyó el bibliotecario estos libros en su lista? ¿Por miedo a la censura? ¿Porque pertenecían a una segunda biblioteca? ¿Porque se adquirieron con posterioridad al trámite del traslado? Descartamos esta última hipótesis

\footnotetext{
1 Su nombre era Juan Francisco Pacheco Téllez Girón, y se convirtió en IV duque de Uceda por su matrimonio con Isabel María Gómez de Sandoval. Era, pues, duque consorte.

2 Martín Velasco, Margarita, La Colección de libros impresos del IV Duque de Uceda en la Biblioteca Nacional de España: estudio y catálogo, Madrid: Calambur, BNE, CEEH, 2009. El expediente principal de nuestro estudio recoge la copia de la petición de licencia que el Sargento Mayor Francisco de Mendita [sic], encargado del transporte del equipaje del Duque, dirige al Revisor de libros y la respuesta de éste una vez hecho el reconocimiento.

${ }^{3}$ La fortuna vino de la mano de Arsenio Sánchez Hernampérez, que en aquel momento estaba restaurando las encuadernaciones del fondo de Uceda. Vaya desde aquí mi gratitud.
}

Titivillus, ISSN 2387-0915, ISSN-e 2603-9966, 1 (2015), pp. 373-388 
porque las fechas de los libros no superan el año 1692 en ningún caso. De aquí el título de mi intervención: aquellos libros fueron invisibles en el viaje a España.

\section{Objetivos}

El tema de la censura de libros ha sido estudiado ya ampliamente. ${ }^{4}$ En el caso de bibliotecas singulares este motivo ofrece, a mi modo de ver, un interés mayor porque nos acerca a la vida de los "usuarios" (como decimos los bibliotecarios), es decir, no solamente del dueño sino también de todos los que se beneficiaron de ella, en los que se aprecia una curiosidad especial y también, quizá, una intención de ocultamiento.

En este artículo nos hemos propuesto acercarnos a los temas que, estando presentes en todas las bibliotecas nobiliarias, sorteaban la censura precisamente por la condición de sus dueños. Enfocando hacia la biblioteca del IV Duque de Uceda nos detendremos en ejemplares concretos que destacan por su curiosidad, por su belleza o por una peculiar fortuna.

\section{Hipótesis para una clasificación temática}

Vamos a partir de un libro perteneciente a la colección que sí fue declarado. Se trata de la obra Pleytos de los libros y sentencias del juez \&o. por el Licenciado Rodrigo Rodríguez, pseudónimo de fray Pedro de Alba y Astorga, publicado en Tortosa en $1664^{5}$ (fig. 1). Este libro comenta multitud de obras

\footnotetext{
${ }^{4}$ J.M. CoetzeE, Contra la censura. Ensayos Sobre la pasión por silenciar, Barcelona, Debate, 2007. Ricardo García CÁRCEL, La Inquisición, Madrid, Biblioteca El Sol, 1990, Antonio MÁrQUeZ, Literatura e Inquisición en España, Madrid, Taurus, 1980. José PARDO TOMÁs, Ciencia y censura: la Inquisición española los libros científicos de los siglos XVI y XVII, Madrid, CSIC, 1991, Marcelin DefourneAux, Inquisición y censura de libros en la España del siglo XVIII, Madrid, Taurus. 1973, JOSÉ PARDO TOMÁs, «Censura inquisitorial y lectura de libros científicos una propuesta de replanteamiento», Tiempos Modernos, 9 (2003-04), pp. 1 18, Henry Kamen, La inquisición española. Mito e Historia, Barcelona, Crítica, 2013, Manuel PEÑA DíAZ, «Identidad, discursos y prácticas de censura inquisitorial (siglo XVII)», Astrolabio. Revista digital del Centro de Investigaciones y Estudios sobre Cultura y Sociedad, 11 (2013), pp. 61-75 (de este autor citamos este reciente artículo, aunque su producción científica sobre el tema es amplia y fundamental).

5 Pedro de Alva y Astorga (1601-1667) fue un franciscano conocido sobre todo por su defensa de la Inmaculada Concepción y sus disputas con los dominicos. Fue Calificador pero también víctima del Santo Oficio. Ingresó en la orden franciscana en Perú, pero viajó a España y a Roma por diversos asuntos y aprovechó bien sus viajes para estudiar en los archivos vaticanos y en la famosa biblioteca Barberini de Roma. Durante tres años regentó la imprenta que los franciscanos tenían en Lovaina, en la cual pretendía publicar su ingente
} 
prohibidas o censuradas, y apoya su información en la Bibliotheca selecta de Antonio Possevino, en la Bibliotheca universalis de Gesner, y en algún otro bibliógrafo más. Es una de esas guías que los bibliotecarios de la época utilizaban para la compra de libros, sobre todo cuando podían adquirirlos fuera de España, como es el caso del Duque de Uceda. Trata también el tema de la autoría de libros que por tradición se asignaban a autores supuestos, manejando sobre todo su conocimiento de escritores franciscanos (alimentando de paso la controversia entre miembros de esta Orden y los dominicos). En realidad era una obra para bibliófilos porque menciona distintas ediciones de los libros en busca de su verdadero autor, etc.

Este ejemplar nos hace volver a considerar la importancia de la intervención del bibliotecario de Uceda en la formación de la colección ya que es bien evidente la presencia de libros de carácter "profesional" que formaban parte de la misma, lo que en aquella época se llamaba apparatus bibliothecae. Estos libros que ahora son instrumentos valiosos para la elaboración de la historia del libro, ya ayudaron a sus poseedores a seguir la fortuna de ejemplares únicos, como estudiamos en su momento. ${ }^{6}$

Puesto que nuestro interés se centra en el contenido de la biblioteca misma, vamos a dejar de lado todo lo relativo a los métodos y mecanismos inquisitoriales en relación con el movimiento de libros, aunque sea asunto de importancia. En cambio, sí hay

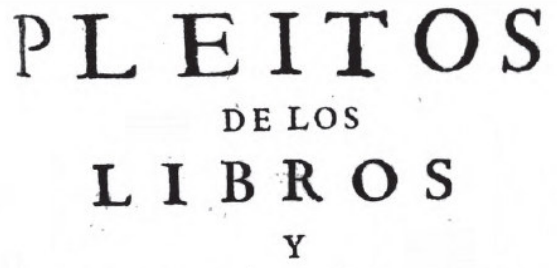

SEN TENCIA S

DE L J UEZ,

\&c.

POR EL LICENCIADO

RODRIGO RODRIGUEZ.

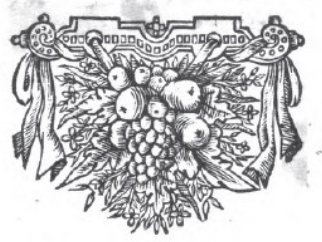

EN TORTOSA

Por Sancho Sanchez. Añode 1664 .

Figura 1: Alva y Astorga, Pedro de, Pleytos de los libros y sentencias del iuez, \&., en Tortosa : por Sancho Sanchez, 1664.

obra en defensa de la Inmaculada Concepción. Lo mencionamos aquí en virtud del rigor bibliográfico con el que trabajaba. Vid. Pleyto de libros y sentencias del juez. BNE, R/6235.

${ }^{6}$ Vid. Margarita MARTín Velasco, «Apparatus bibliothecae: una bibliografía del siglo XVII sobre biblioteconomía», en María Teresa FERNÁNDEZ BAjÓN, (coord.), Estudios de biblioteconomía y documentación. Homenaje a la profesora María Rosa Garrido Arilla", Madrid, Escuela Universitaria de Biblioteconomía y Documentación, 2004, pp.189-200.

Titivillus, ISSN 2387-0915, ISSN-e 2603-9966, 1 (2015), pp. 373-388 
que poner de manifiesto lo ineficaces que fueron esos mecanismos en este caso, ya que tanto por el número de libros como por su cualidad parece al menos sorprendente que pasaran inadvertidos. En este sentido cabe aventurar la hipótesis de la segura amistad que vinculaba al entonces virrey de Sicilia, dueño de la biblioteca, y al Inquisidor de ese reino en el momento que contemplamos, de nombre Diego Vicencio de Vidania, escritor a su vez, y seguramente "usuario" de la buena biblioteca virreinal. 7 Estoy de acuerdo con la conclusión a la que llega Eugenio Asensio respecto a que "la Inquisición en sus ambiciones de fiscalizar y expurgar una inmensa mole de libros, no contaba con el apoyo claro del Poder ni de las clases gobernantes, cuya ayuda era tibia y con fronteras personales". ${ }^{8}$

Si el catálogo de obras declaradas daba una cifra de 2076 registros, muchos de ellos correspondientes a obras con varios volúmenes, el número de libros no declarados y que pueden reconocerse como procedentes de la colección por sus características externas, es de unos 400. En la actualidad están repartidos en los distintos depósitos de la Biblioteca Nacional. No podemos contar los que, por circunstancias diversas, estén en otras bibliotecas o hayan perdido su característica encuadernación verde.

El primitivo catálogo estaba bien estructurado temáticamente según un orden doble: primero por materias y luego por tamaños. La lista describe los libros de mayor formato en primer lugar, dentro de cada apartado. La clasificación de este nuevo fondo es solamente una propuesta nuestra, de carácter hipotético, y está enfocada a descubrir las posibles causas de su censura, pues hemos encontrado también muchos ejemplares fuera de toda sospecha de prohibición de los cuales no vamos a hablar por razones obvias.

En aras de la brevedad, examinaremos algunos casos. La presencia de libros sobre magia en esta biblioteca tiene el valor que la misma ciencia le había otorgado en aquel momento de pre-ilustración: para aquellos lectores la realidad era mágica en tanto que la ciencia no encontrase explicaciones, y no podemos olvidar el enorme número de libros científicos que el Duque tenía. La magia era casi un estímulo para los amantes de la ciencia. En este contexto, nada tiene que ver la lectura de libros de autores como Paracelso en épocas anteriores.

Tanto el coleccionismo de rarezas como el amor a la ciencia que caracterizan a los nobles de esta época ponen de manifiesto una aproximación a la naturaleza que se acerca mucho al mundo de la magia. Un buen ejemplo de esto es la presencia de una piedra bezoar en el inventario post mortem de los

\footnotetext{
7 Vid. Antonio Roldán PÉREZ, «Reflexiones sobre la producción literaria de los funcionarios inquisitoriales», en José Antonio Escudero (ed.), Perfiles jurídicos de la Inquisición Española, Madrid, Instituto de Historia de la Inquisición, 1989, pp. 477-511.

8 EugENIO ASENSIO, «Censura inquisitorial de libros en los siglos XVI y XVII. Fluctuaciones. Decadencia», en El libro antiguo español... María Luisa LÓPEZ-VIDRIERO, et al., (eds.), Salamanca, Ediciones de la Universidad de Salamanca, 1988, p.36
} 
bienes que el Duque tenía en su gabinete de Viena, cabría preguntarse: ¿habrá alguna razón científica para encontrar poderes curativos especiales en este extraño objeto? No hay ninguna semejanza en esta cuestión con el espíritu medieval de asombro ante lo oculto, sino con una curiosidad que les lleva a indagar sobre las leyes físicas en un intento de averiguar sus maravillas. Si en la Edad Media el misterio de lo desconocido atribuye poderes divinos al que sabe copiar las leyes naturales, bien desde la alquimia, bien desde la astrología, ahora son tema de estudio esas mismas leyes, las que mueven los astros en el cielo, los humores en el cuerpo, la fuerzas telúricas en el interior de la tierra y hasta las disposiciones anímicas. Todo puede tener una explicación. En su doble función representativa y erudita, esta biblioteca invisible nos hace imaginar un universo vivo e intercomunicado, lleno de signos (fig. 2).

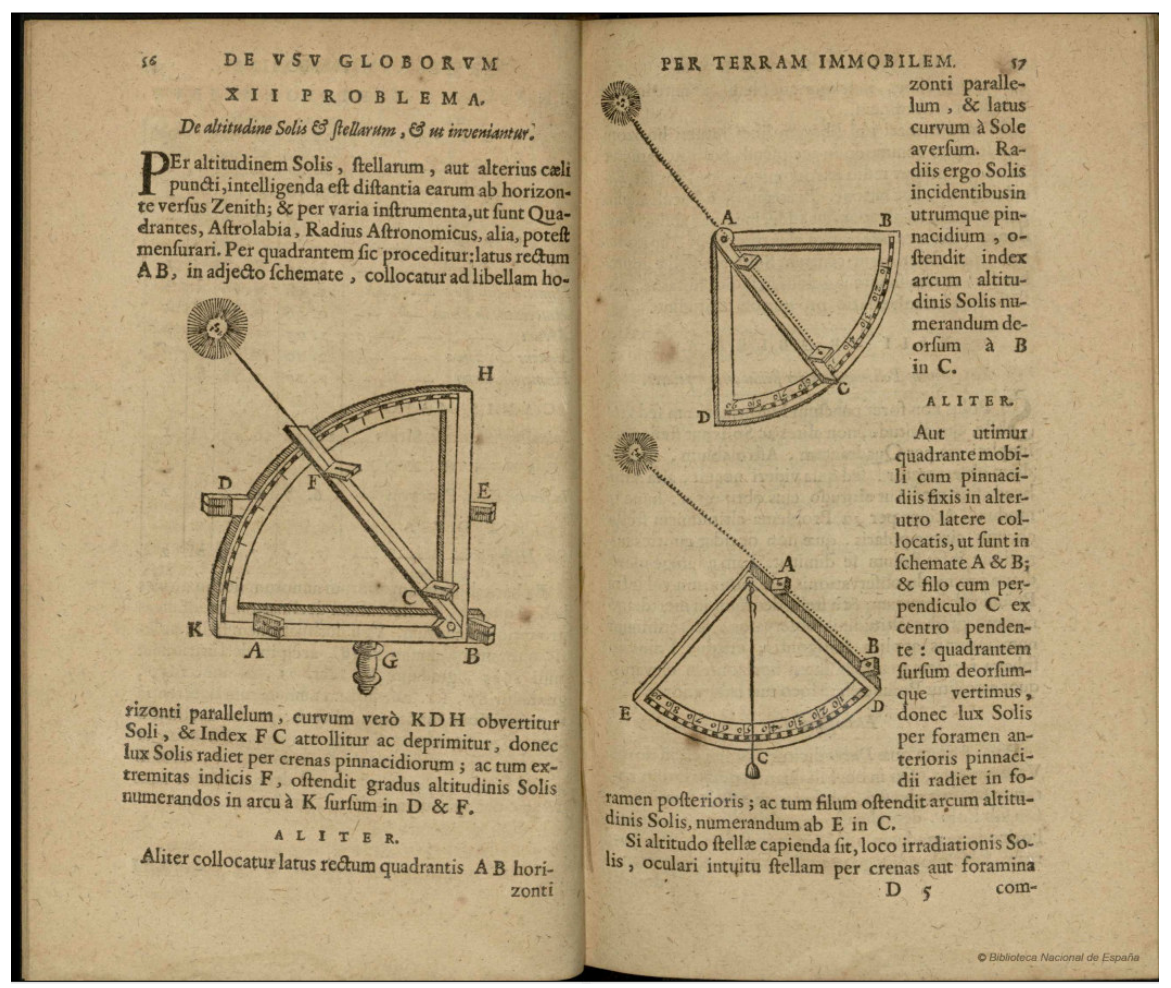

Figura 2: Guilielmi Blaeu, Institutio Astronomica,Amstelodami, 1634. BNE, GMM/2913. 

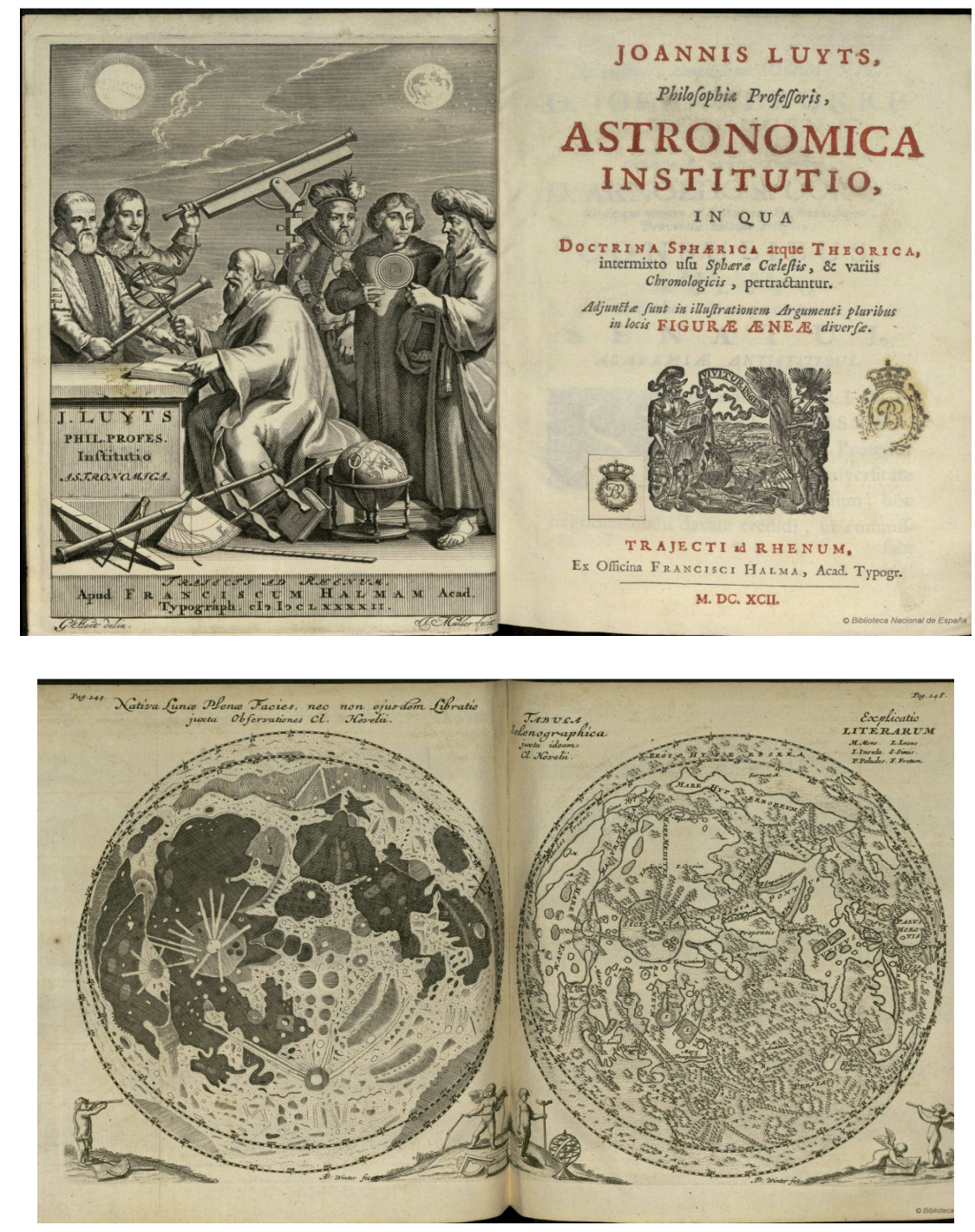

Figura 3: Luyts, Joannis, Institutio Astronomica, Traiecti Rhenum, 1692. BNE, GMM/2982.

Para mí es imposible evitar la pregunta sobre si estos libros eran comprendidos. ${ }^{9}$ La visión de larguísimos textos en latín y griego, con multitud

${ }^{9}$ Me lo pregunto tras la lectura del Elogio de la locura de Erasmo, quien hablando de los filósofos dice: "desprecian al profano vulgo solo porque saben trazar triángulos, cuadriláteros, círculos y otras figuras matemáticas, inscritas unas en otras, e intrincadas en forma laberíntica y acompañadas de un ejército de letras, repetidas en distintos órdenes, cuya colocación ofusca a los ignorantes. No faltan algunos entre ellos que leen el porvenir 
de tablas, símbolos, cifras y grabados, junto con la presencia de instrumentos como telescopios, esferas armilares, y otros objetos de medición propios de esas estancias descritas en el testamento del Duque de Uceda me induce a pensar que la interpretación de su significado era mucho mayor de lo que podríamos imaginar (figs.3, 4 y 5). Había libros de magia en la biblioteca que los duques de Osuna tenían en el palacio de El Capricho de Madrid, en la del Marqués del Carpio, en la del Marqués de Astorga, e incluso en la del escultor Pompeo Leoni (cuya vida en la corte llegó a asimilarse socialmente a la de los nobles que contrataron sus servicios), etc., pero, naturalmente, no existía un apartado con tal enunciado en sus catálogos. ${ }^{10}$

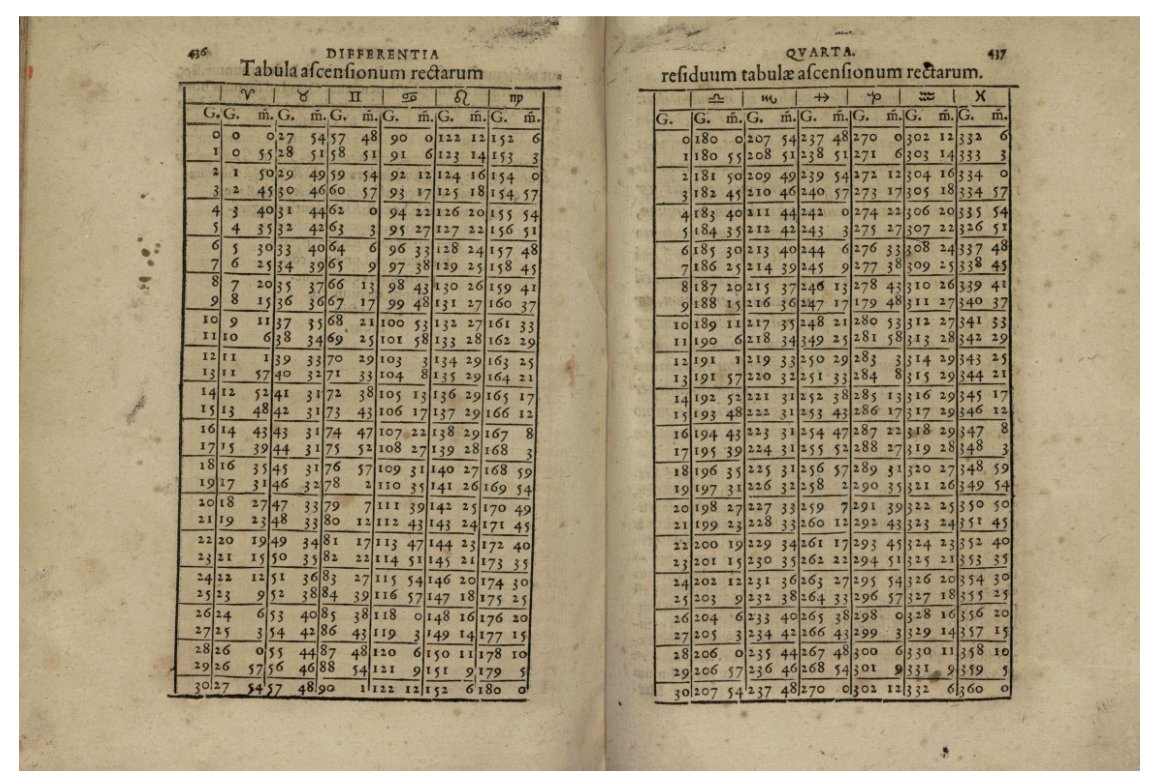

Figura 4: Naiboda, Valentin, Enarratio elementorum astrologiae, Coloniae : apud haeredes Arnoldi Birckmanni, 1560. BNE GMM/2538.

en los astros, y que prometen milagros mayores que los de la magia”, p. 181 en la edición Aguilar de 1970, traducción de A. Rodríguez Bachiller, sobre la de Frobenio de 1515.

10 Vid. $\mathrm{M}^{\mathrm{a}}$ Isabel Pérez Hernández, «Análisis de la Obra Asuntos de brujas de Goya para la casa de campo de la Duquesa de Benavente», AXA, Una revista de Arte y Arquitectura, octubre 2012, PEDRO M.CÁTEDRA, Nobleza y lectura en tiempos de Felipe II: la biblioteca de don Alonso Osorio, marqués de Astorga, Valladolid, Junta de Castilla y León, 2002, Kelley HeLmSTUTLER DI DIO, «The chief and perhaps only antiquarian in Spain, Pompeo Leoni and his collection in Madrid», Journal of History of Collections, 18 (2006), pp. 137-67, Pilar AlONSO PALOMAR, «La importancia de la magia a la luz de los libros contenidos en algunas bibliotecas particulares españolas de los Siglos de Oro», Castilla: Estudios de literatura, 22 (1997), pp. 21-36. 


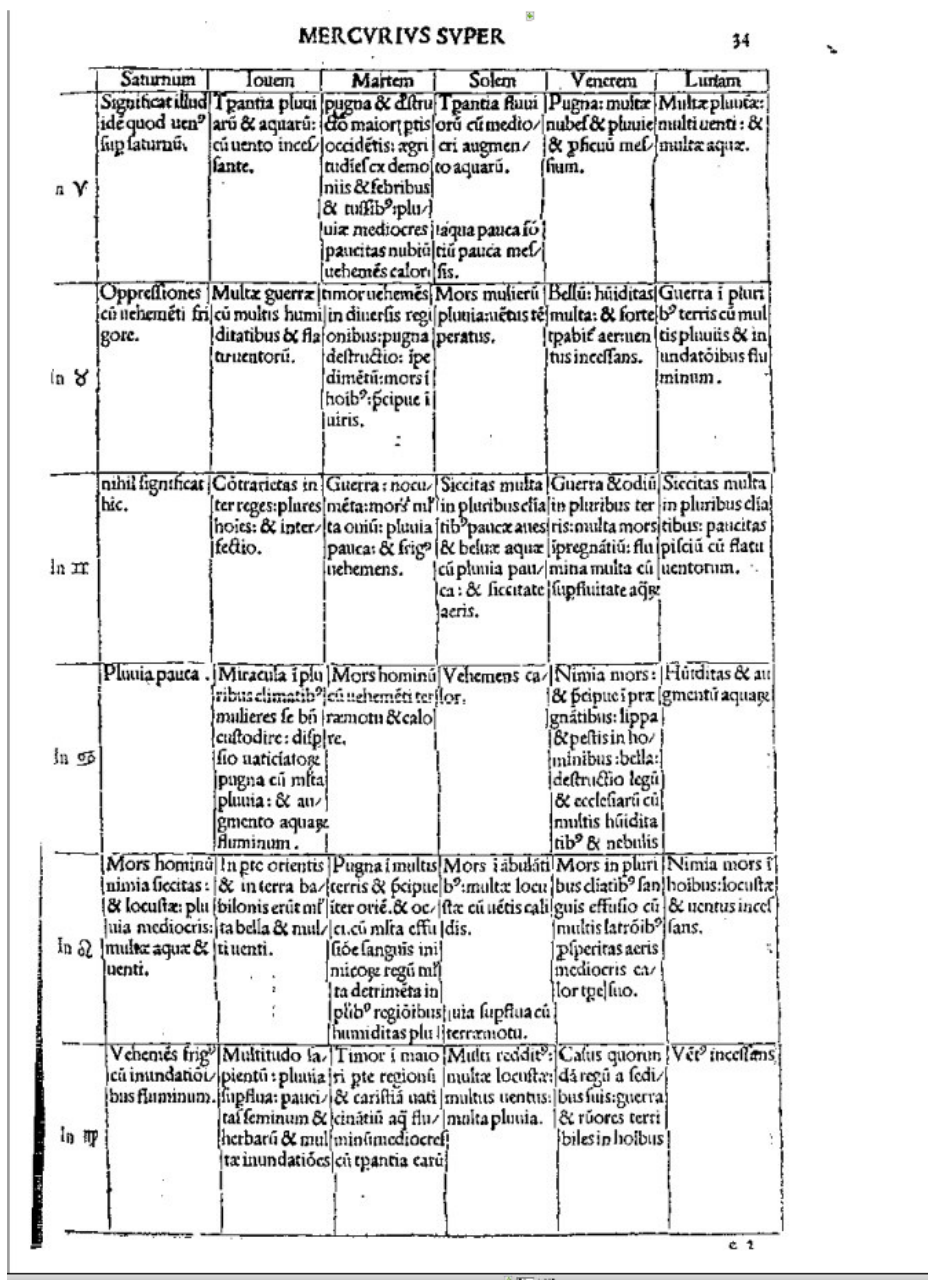

Figura 5: Eschuid, Johannes, Summa astrologiae iudicialis de accidentibus mundi, Venezia : Johannis Lucilius Santritter [typ. Hieronymi de Sanctis] : impens. Francisci Bolani, 7 julio, 1489. BNE, Inc/1325.

Otros autores ${ }^{11}$ han puesto de manifiesto el hecho de que la Inquisición distinguía entre dos categorías de lectores en función de su conocimiento del idioma latino, y que las ediciones en dicha lengua estarían autorizadas, en consideración de la formación que los lectores tendrían, pero no así sus traducciones, destinadas a un público generalmente menos cultivado.

11 Vid. Asensio, «Censura inquisitorial de libros en los siglos XVI y XVII. Fluctuaciones. Decadencia», pp. 21-36. 
Esto nos lleva a reflexionar sobre el caso de Erasmo. Tanto el pensamiento como la forma de exposición del ilustre holandés habían perdido vigencia en 1692, pero seguía siendo una señal de cultura la presencia de sus libros en este tipo de bibliotecas. Los libros que hemos encontrado son dos obras fundamentales: Colloquia, publicado en Lugduni Batavorum y Roterodami, Officina Hackiana, 1664 y Apophthegmata ex probatis graecae latinaeque lingva scriptoribus, publicada en Genevae en 1668, en su versión original latina. En el segundo, el lugar de edición está tachado y esa es la única marca de censura que aparece. En ambos casos no se trata de traducciones, es decir, no pasaron por el tamiz del espíritu con que trabajaron los erasmistas españoles al hacer las traducciones analizadas por Bataillon. Son dos de las obras que el mismo Erasmo prefería que se leyeran en latín. ${ }^{12}$ Es más, los Colloquia están concebidos como un método de enseñanza del latín a los jóvenes, motivo por el cual es uno de libros más leídos de Erasmo incluso en el siglo XVII (fig. 6)

De los Colloquia no me resisto a comentar la dedicatoria que Erasmo brinda al hijo de su editor y querido amigo Frobenio (Frobenius), en el que adopta un tono paternal aconsejándole que no defraude las esperanzas que tanto su padre como él mismo tenían en su persona. Le anima al estudio y al ejercicio de las virtudes en un latín sencillo y pedagógico.

El número de libros de temática médica en la biblioteca "declarada" de nuestro duque es de 74, algunos con varios volúmenes. Hipócrates, Galeno, Avicena y autores contemporáneos como el médico napolitano Leonardo di Capua (1617-1695) llenaban la estantería décima de su biblioteca. Allí debía encontrarse también la obra de Daniel Sennert (1572-1637) no mencionada por el bibliotecario en su catálogo. Este autor fue profesor de medicina en la Universidad de Wittenberg. José Pardo sigue el itinerario de sus libros en el Index :

La peripecia de este autor en los índices es compleja. En 1632 (p. 239) Y 1640 (p. 252) aparece en la primera clase un «Daniel Semestus. Medicus», que no es otro que Sennert según afirma Ponce de León, un calificador del Santo Oficio a quien le entregarán en 1647 las Opera omnia (Lyon, 1641) de Sennert para que las examine (AHN, leg 4440, 4). Durante treinta y dos años, la obra de Sennert estará prohibida y sus ejemplares peregrinarán por varios tribunales, serán calificados una y otra vez, y solamente en 1679 se dictaminará definitivamente: la obra debe expurgarse

12 Vid. el capítulo «La invasión erasmiana. Traducciones castellanas de Erasmo (15271532)», en Marcel Bataillon, Erasmo y España, Méjico, FCE, 1966.

Titivillus, ISSN 2387-0915, ISSN-e 2603-9966, 1 (2015), pp. 373-388 
para eliminar dos proposiciones sobre el alma humana que se consideran heréticas según una calificación en $1677 .{ }^{13}$
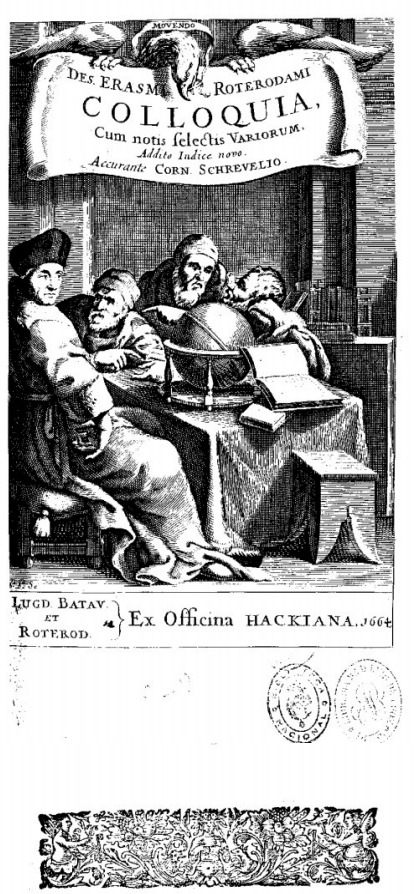

DES. ERASMUS ROTEROD OPTIMES SPEI PUERO

JOHANNI ERASMIO

FR OBENIO S. $\mathcal{D}$.

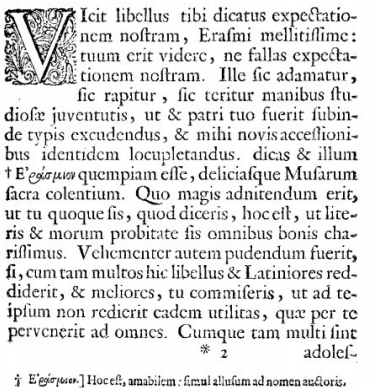

Figura 6: Erasmus, Desiderius, Colloquia, Officina Hackiana, 1664.

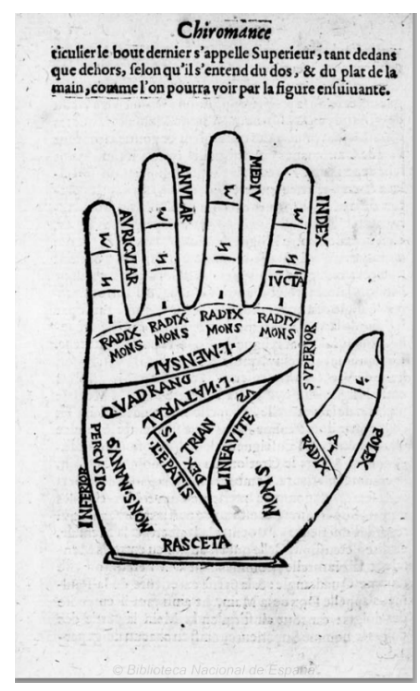

$$
\text { DEDICA T Y O. }
$$

dolefcentes, qui tibi nomine Colloquiorum gratias agunt; nonne merito cenfeatur abfur. dum, fi tua culpa factumvideatur, quo minu: mihipolfis eodem nomine gratias agere? Accre.
vit libel'us ad juftam voluminis magnitudinem vit libel'us ad juftam voluminis magnitudinem.
tibi quoq le conandum eft, ut quantum accrefćit $x$ tas, tantum accedar \& honction morum integritati. Suftines non vulgarem ex. cere pulcherrimum fuerit: certe fallere fine fum. mo dedecore non potes. Nec hoc dico, quod hactenus poeniteat profectus tui, fed utcurren. ticalcar addam, quo curras alacrius. prefertim cum camæetatemingreflus fis, qua non alia con. tisiemina. Facigitur, tis emina. Facigitur, ut hxc colloquia vere tua
dici poffint. Dominus Jefus fervet iftam ratem tuam puram ab omnibus inquinamentis, fem. perque ad meliora provehat. V
Kalend. Auguft. Anno M D xxiv.

13 Vid. José PARDo TOMÁs, «El paracelsismo europeo en los índices inquisitoriales españoles (1583-1640)», Arbor, Madrid, CSIC, 1986. 
Quizá el apartado más intencionalmente ocultado de la colección sea el formado por los libros de adivinación y quiromancia (fig. 7). La cuestión de fondo que, en su momento, la Inquisición pretendía preservar con la prohibición de estos libros es nada menos que la doctrina del libre albedrío frente a la predeterminación que pudiera sugerir la adivinación de los signos corporales, sobre todo las manos, o los que muestra la naturaleza. Esta cuestión ya no era tan debatida en 1692. El ejemplar de Taisnier que hemos tomado como ejemplo en la colección de Uceda está intacto, mientras que el que se conserva en la Biblioteca Marqués de Valdecilla de la Universidad Complutense tiene multitud de pasajes tachados por el censor (figs. 8 y 9). En este ejemplar complutense, además, se advierte que procede de la venta de duplicados de la biblioteca de El Escorial y contiene el sello de la Biblioteca Real, lo cual quiere decir que pertenecieron ambos ejemplares al mismo fondo durante algún tiempo (desde la fundación de la Real Biblioteca hasta que se efectúa la venta, bien entrado el siglo XVIII).

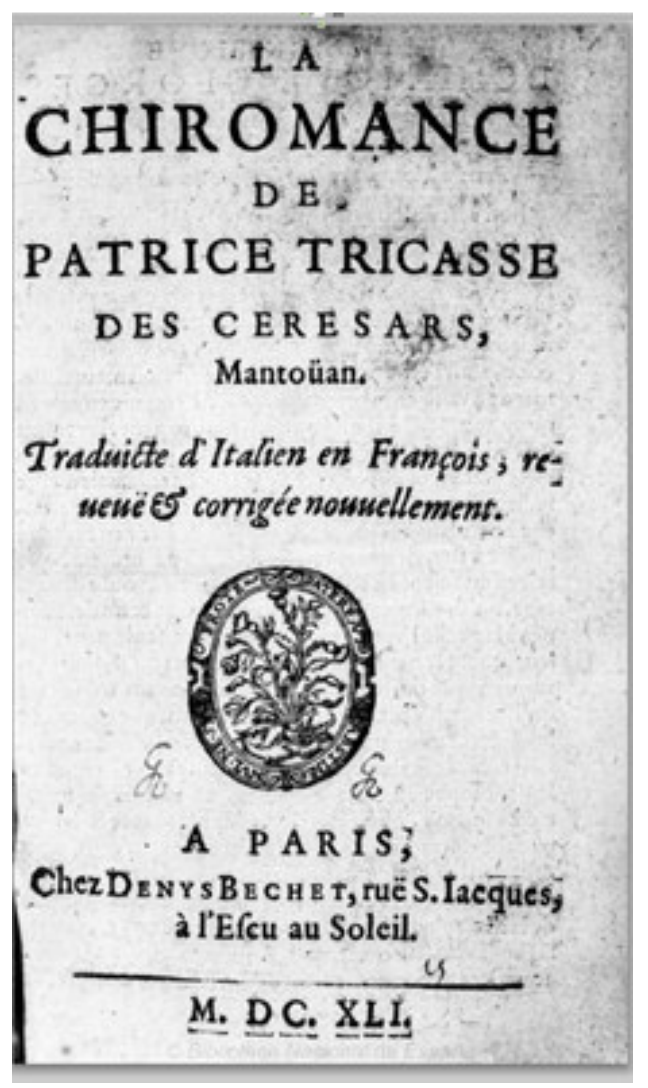

Figura 7: Tricasse, Patrice, La Chiromance, a Paris, 1641. BNE 2/94651

Titivillus, ISSN 2387-0915, ISSN-e 2603-9966, 1 (2015), pp. 373-388 


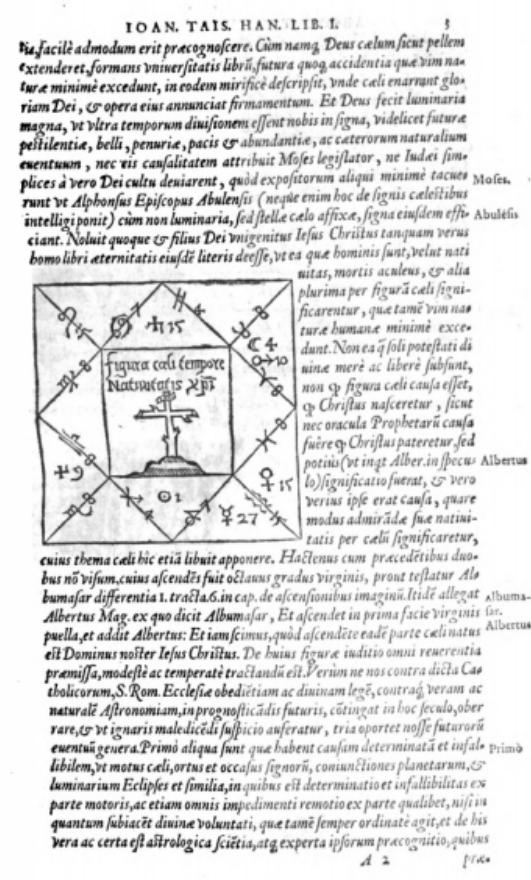

Figura 8: Opus mathematicum octo libros complectens, innumeris propemodum figuris idealibus manuum et physiognomiae, aliisque adornatum, Taisnier, Johannes, Coloniae Agrippinae : apud Ioannem ckmannum et

Wernerum Richwinum..., 1562. BNE, 3/13684. Página 3.

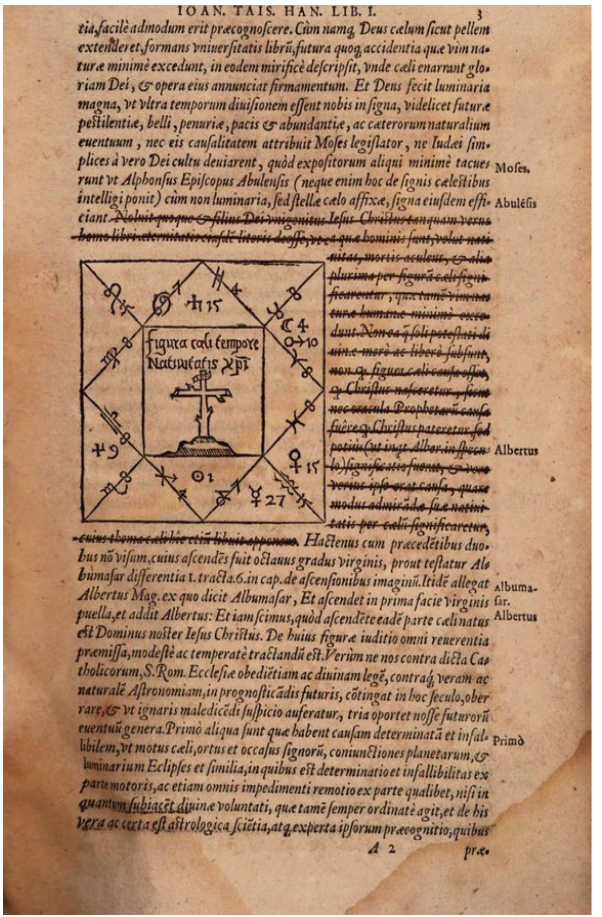

Figura 9: Opus mathematicum octo libros complectens, innumeris propemodum figuris idealibus manuum et physiognomiae, aliisque adornatum, Taisnier, Johannes, Coloniae Agrippinae : apud Ioannem Birckmannum et Wernerum Richwinum..., 1562. Biblioteca UCM. BH FLL 14738. Página 3.

Hay otros dos libros más que merecen nuestra atención. El primero de ellos, la Hypnerotomachia Poliphili, por su singularidad estética; y el segundo, una obra censurada por la inquisición romana -que no por la española-, por ser una crítica directa a lo que ahora llamaríamos política vaticana, Vita di Donna Olimpia Maldachini, de un tal Abad Gualdi que no es otro que Gregorio Leti, un autor especializado en la "prensa amarilla" de la época.

Ciertamente, no podía faltar la obra de Colonna en la biblioteca de un hombre de gusto tan refinado. La Hypnerotomachia Poliphili es un libro muy estudiado, de extraño contenido, que ha sido objeto tanto de análisis bibliográfico como de argumento literario. Este libro no fue censurado por su texto sino por sus ilustraciones (fig. 10)..$^{14}$

14 Vid. Colonna, Francesco, Sueño de Polifilo, Madrid, Acantilado, 2008, traducción de Pilar Pedraza. 
loco \&conditione era di piacere $\&$ contento, \& la benignitate lua, colum binulamente bafciantime \& ftrictamente amplexantime, da me chiedetelicentia\& cummeato.

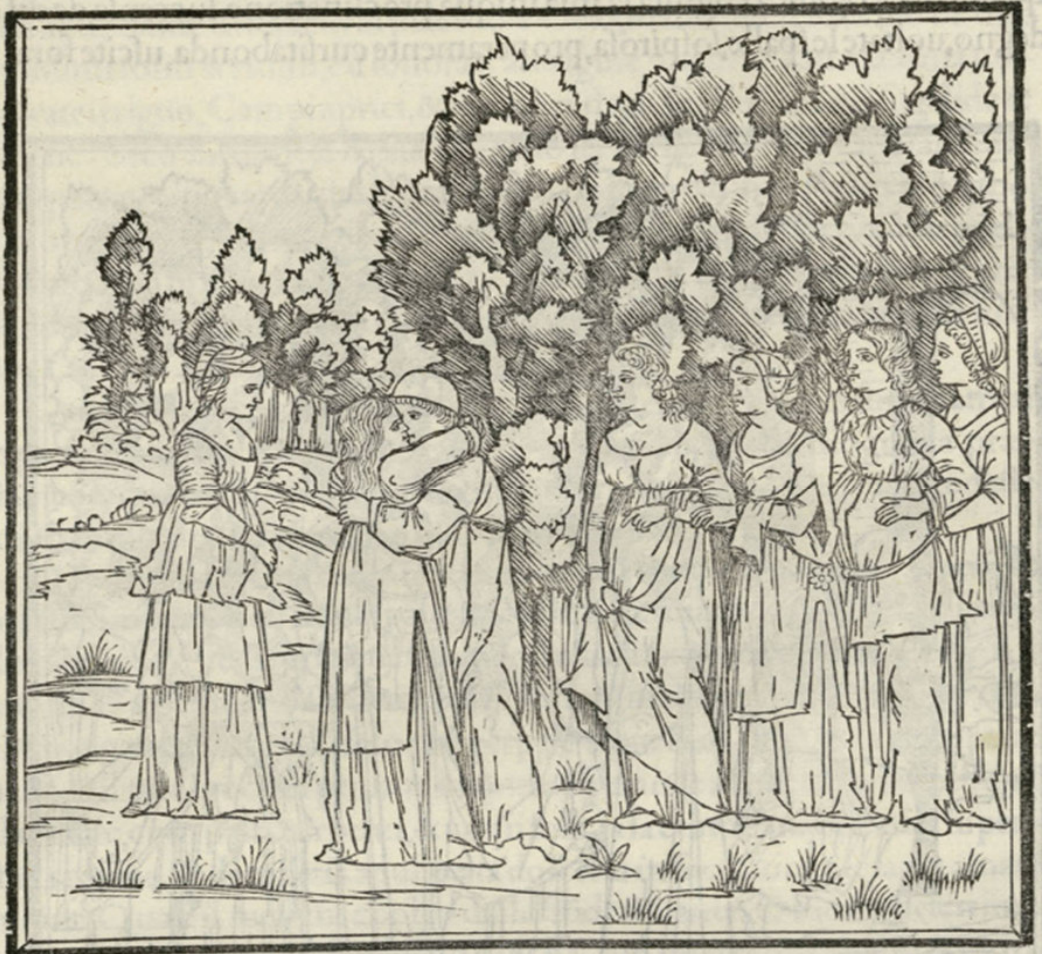

Et reclufele metalline ualue, rimanfi clauftrato'immediate tra quelle egregie Nymphe,Lequale meco lepidiffime\&lafciuule incominciorono dantorno afcherciare, \& uallato dalla uoluptica caterua delle quale,

Figura 10 . Hypnerotomachia Poliphili, Venetia, 1499. p. 148. BNE, I/1357. Pág. 148

A título indicativo se registran algunos títulos en el siguiente cuadro sinóptico: 


\begin{tabular}{|c|c|c|c|}
\hline Tema & Ejemplos & & $\begin{array}{l}\text { Signatura } \\
\text { BNE }\end{array}$ \\
\hline Astrología & $\begin{array}{l}\text { Status Astrologicus: Anacephalaeosis } \\
\text { Bocarro, Manuel }\end{array}$ & $\begin{array}{ll}\text { Predicciones } & \text { astrológicas } \\
\text { sobre las } & \text { monarquías } \\
\text { europeas } & \end{array}$ & $2 / 55780(2)$ \\
\hline Doctrina: Erasmo & $\begin{array}{l}\text { 1. Colloquia } \\
\text { 2. Apophthegmata ex probatis graecae } \\
\text { latinaeque lingva scriptoribus }\end{array}$ & Lugar de edición tachado & $\begin{array}{l}2 / 69602 \\
2 / 94354\end{array}$ \\
\hline $\begin{array}{l}\text { Doctrina: } \\
\text { Otros }\end{array}$ & $\begin{array}{l}\text { 1.Hypnerotomachia Poliphilo } \\
\text { 2. Vita di Donna Olimpia } \\
\text { Maldachini: che gouernó la Chiesa, } \\
\text { durante il Ponteficato d'Innocentio X } \\
\text { cioè, doppo l'anno } 1644 \text { sino all'anno } \\
1655 \text { / scritta Dall'abbate Gualdi }\end{array}$ & $\begin{array}{l}\text { Magnífica edición aldina de } \\
\text { 1499, con ilustraciones } \\
\text { Prohibido por la Inquisición } \\
\text { romana }\end{array}$ & $\begin{array}{l}\mathrm{I} / 1357 \\
3 / 23092\end{array}$ \\
\hline Medicina & $\begin{array}{l}\text { Opera omnia medica, Sennert, } \\
\text { Lugduni, } 1676 \text { (3 vol.) }\end{array}$ & $\begin{array}{l}\text { El libro fue expurgado con } \\
\text { posterioridad al ingreso en la } \\
\text { Real Biblioteca, en } 1738\end{array}$ & $2 / 3859-3861$ \\
\hline $\begin{array}{l}\text { Quiromancia } \quad y \\
\text { adivinación }\end{array}$ & $\begin{array}{l}\text { 1. La chiromance, Tricasso, } \\
\text { Patrizio } \\
\text { 2. Opus mathematicum, Taisnier, } \\
\text { Johannes }^{15}\end{array}$ & & $\begin{array}{l}2 / 94651 \\
3 / 13684\end{array}$ \\
\hline
\end{tabular}

\section{Conclusiones}

Como conclusión a este adelanto del estudio del catálogo de los libros que pertenecieron a don Juan Francisco Pacheco en Palermo y que no declaró en su traslado a Madrid podemos destacar tres aspectos:

En primer lugar contemplamos que ya en esta época (1692) la censura era menos estricta con los lectores que con los escritores, y en el caso concreto de bibliotecas particulares de personajes de la alta nobleza (como en el que nos ocupa) podríamos decir que los encargados del Santo Oficio eran más permisivos y no ejercían un control riguroso sobre los libros declarados, no admitían fácilmente sospechas hacia posibles libros no declarados.

En segundo lugar, en cuanto a los libros de data anterior descritos en el Index, su presencia en bibliotecas de esta época puede interpretarse como hábito de bibliófilo o de coleccionista sin que suponga una adhesión a una corriente ideológica. La biblioteca de un noble era un signo representativo importante de su dignidad y su cultura y en ella no podían faltar ciertos autores o temas, lo cual no quiere decir que su dueño los hubiera leído o hubiera manifestado un gusto personal hacia ellos. En el caso de esta biblioteca, apenas hay huellas de uso.

15 Opus mathematicum octo libros complectens, innumeris propemodum figuris idealibus manuum et physiognomiae, aliisque adornatum ... Johannes TAISNIER, Coloniae Agrippinae : apud Ioannem Birckmannum et Wernerum Richwinum..., 1562. BNE, 3/13684 
Por último, y desde el punto de vista de la ideología, los ejemplares censurables pertenecían más bien al Renacimiento que a la época pre-ilustrada de 1692. En cuanto a la abundancia de ciertos libros de quiromancia o adivinación podemos aventurar que provinieran de una misma almoneda y que los agentes de Uceda adquirieran un fondo completo de carácter cuanto menos curioso. Así fue como Uceda construyó la sección histórica de su biblioteca, con los libros de Antonio de Solís o Jerónimo de Mascareñas, aunque este aspecto debe ser estudiado más en profundidad. La presencia de libros de carácter filosófico o científico "pasados de moda" podría significar lo mismo que significa su presencia en nuestras propias bibliotecas domésticas actuales: los libros de Erasmo, Copérnico, etc., evidencian su valor testimonial y cultural del pensamiento de una época, y por ello no han dejado de editarse nunca. 